\title{
Transient Left Ventricular Outflow Obstruction in Tako Tsubo- Syndrome: A Case Report
}

\author{
Nilda Espinola-Zavaleta ${ }^{1,3 *}$, Moisés Levinstein-Jacinto ${ }^{2}$, Victor M Ocana-Arriaga ${ }^{2}$ and Manuel de la Llata-Romero ${ }^{2}$ \\ ${ }^{1}$ Department of Nuclear Medicine, National Institute of Cardiology Ignacio Chavez, Mexico City, Mexico \\ ${ }^{2}$ Coronary Care Unit ABC Medical Center IAP, Mexico City, Mexico \\ ${ }^{3}$ Department of Echocardiography, ABC Medical Center IAP, Mexico City, Mexico
}

\begin{abstract}
This is a clinical case of an 83-years-old woman referred to our hospital for the occurrence of chest pain and syncope, related to an intense emotional stress in the previous three months. At admission, the electrocardiogram showed S-T segment elevation from V1-V3 and deep inversion of the T-wave in V4-V6, and an increase in troponin I level $(6.4 \mathrm{ng} / \mathrm{mL})$. Echocardiogram demonstrated midapical segment akinesia with left ventricular dysfunction. Basal segments were hypercontractile and there was evidence of left ventricular outflow tract (LVOT) obstruction with an end-systolic peak gradient of $99 \mathrm{mmHg}$. Regression of the LVOT obstruction was detected at third day. Three weeks after admission a serial two-dimensional echocardiography and nuclear medicine studies showed a complete regression of the left ventricular wall motion abnormalities with an improvement of systolic function.
\end{abstract}

Keywords: Chest pain; Coronary syndrome; Left ventricular outflow tract; Echocardiography

Abbreviations: LVOT: Left Ventricular Outflow Tract; ECG: Electrocardiogram

\section{Introduction}

The shape of apical ballooning associated with basal hyperkinesis and apical akinesis is described as Tako Tsubo cardiomyopathy, mimicking a fishing pot with a narrow neck and wide base that is used to trap octopus in Japan [1]. Conceivably, emotional or physical stress plays a crucial role in causing left ventricular dysfunction [2,3].

Some cases of LVOT obstruction after Tako Tsubo syndrome were reported $[4,5]$. The aim of this study is to describe the features of transient LVOT obstruction in an 83-years old woman with Tako Tsubo syndrome.

\section{Case Report}

An 83-year old woman was referred to the emergency department of our hospital for the occurrence of chest pain with radiation to the left arm and syncope, accompanied by intense emotional stress in the previous three months (her daughter had been diagnosed with advanced gallbladder cancer) and before the cardiovascular event her granddaughter had an automobile accident which provoked a medullar injury and paraplegia).

At admission, she was hypotensive; the electrocardiogram (ECG) showed S-T segment elevation (Figure 1) from V1-V3 and deep inversion of the T-wave in V4-V6. There was an increase in troponin I level $(6.4 \mathrm{ng} / \mathrm{mL})$, and signs of pulmonary congestion in the chest radiograph (Figure 2). A verbal report of a previous transthoracic echocardiography indicated left ventricular systolic dysfunction (ejection fraction 30\%) and akinesis of the interventricular septum and anterior wall of the left ventricle. The echocardiogram performed in our institution at her admission showed akinesis of the middle and apical segments of the interventricular septum and anterior wall with hypercontractility of the basal segments (Figure 3A). There was evidence of systolic anterior motion of mitral valve and septal bulge provoking dynamic obstruction of the Left Ventricle with an endsystolic peak gradient of $99 \mathrm{mmHg}$ (Figure 3B).
A sharp decrease in troponin I levels was registrated in the following days (Table 1). A serial echocardiographic examination was performed 3 days later and a regression of LVOT obstruction was detected with persistence of apical akinesis (Figure 3C). Three weeks later the left ventricular wall motion normalized and an improvement in systolic function was observed (Figure 3D). The serial ECG showed normalization of the $\mathrm{S}$-T segment elevation and persistence of inverted T-waves.

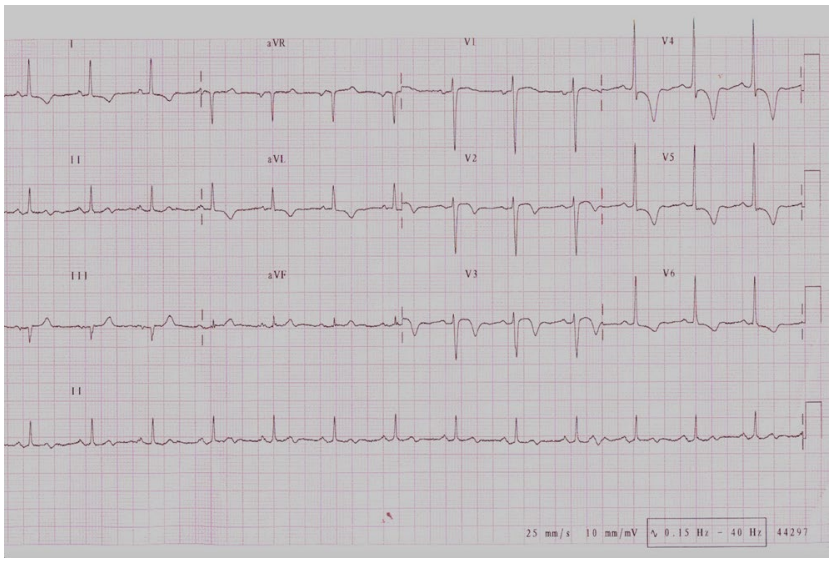

Figure 1: The electrocardiogram at admission showed ST-segment elevation from V1.-V3 and deep inversion of T-wave in V4-V6.

*Corresponding author: Nilda Espinola-Zavaleta, Department of Echocardiography, National Institute of Cardiology Ignacio Chavez, Mexico City, Mexico, Tel: 55732911; E-mail: niesza2001@hotmail.com

Received November 16, 2017; Accepted December 11, 2017; Published December 17, 2017

Citation: Espinola-Zavaleta N, Levinstein-Jacinto M, Ocana-Arriaga VM Llata-Romero M (2017) Transient Left Ventricular Outflow Obstruction in Tako Tsubo- Syndrome: A Case Report. J Vasc Med Surg 5: 350. doi: 10.4172/23296925.1000350

Copyright: () 2017 Espinola-Zavaleta N, et al. This is an open-access article distributed under the terms of the Creative Commons Attribution License, which permits unrestricted use, distribution, and reproduction in any medium, provided the original author and source are credited. 


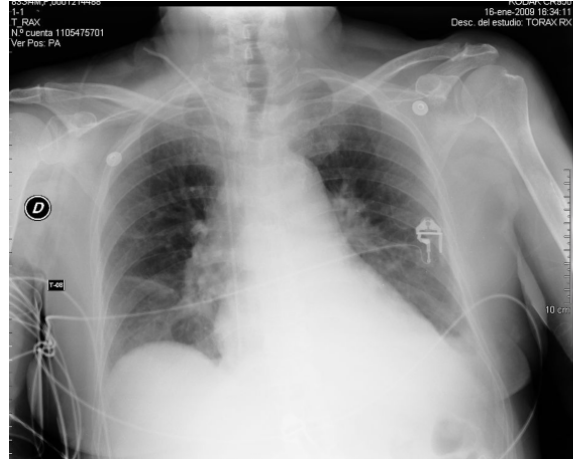

Figure 2: In an X chest-ray pulmonary congestion was observed.

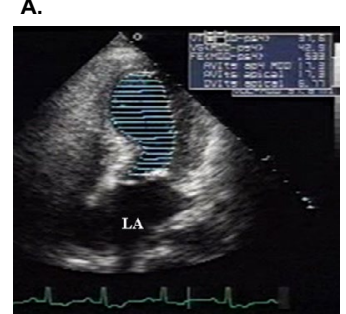

C.

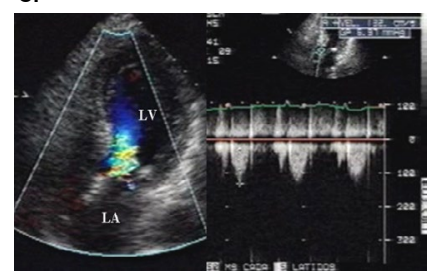

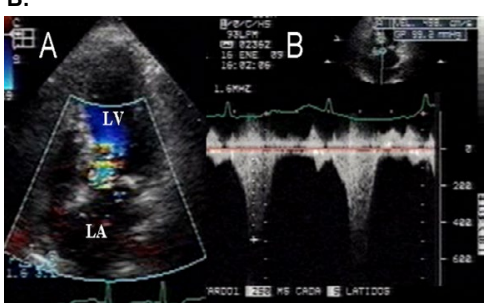

D.

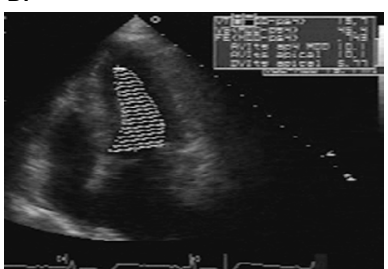

Figure 3: Two-dimensional, color and continuous wave Doppler echocardiographic images in an apical 4-chamber view was performed, (A) Akinesis of the middle and apical portions of the interventricular septum is observed. The left ventricular function is normal, because hypercontractility of the basal segments. (B) A LVOT obstruction with a peak gradient of $99 \mathrm{mmHg}$ was detected. (C) After 3 days a complete regression of dynamic obstruction was found, but a persistence of apical hypokinesis was observed. (D) Three weeks later no wall motion abnormalities were observed and the left ventricular function was improved.

\begin{tabular}{|c|c|c|c|}
\hline $\mathbf{1 6} / \mathbf{0 1 / 2 0 1 5}$ & $\mathbf{1 7 / 0 1 / 2 0 1 5}$ & $\mathbf{1 8 / 0 1 / 2 0 1 5}$ & $\mathbf{1 9 / 0 1 / 2 0 1 5}$ \\
\hline $6.4 \mathrm{ng} / \mathrm{mL}$ & $3.3 \mathrm{ng} / \mathrm{mL}$ & $1.9 \mathrm{ng} / \mathrm{mL}$ & $1.3 \mathrm{ng} / \mathrm{mL}$ \\
\hline
\end{tabular}

Table 1: Troponin I level.

The nuclear medicine studies at the third day of hospitalization showed mild to moderate left ventricular myocardial ischemia in the anterior, septal and inferior walls in the middle and apical portions. After 3 weeks these changes disappeared and the systolic function was improved (Figure 4). No coronary angiography or computed tomography was performed, because of chronic renal insufficiency with creatinine level of $4.5 \mathrm{mg} / \mathrm{dL}$.

She received treatment with nitrates, aspirin, and heparin and now she is without cardiovascular symptoms.

\section{Discussion}

Tako-Tsubo syndrome, also called stress cardiomyopathy or transient left ventricular apical ballooning syndrome is a clinical entity mimicking an acute coronary syndrome [6]. The characteristics of

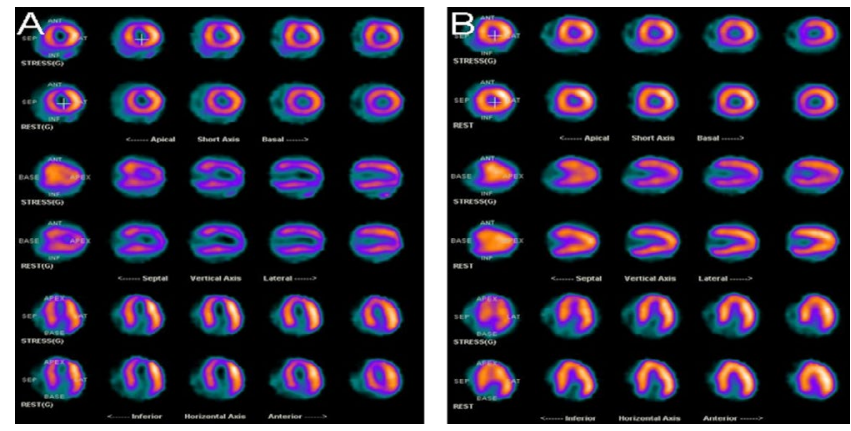

Figure 4: (A) Mild to moderate ischemia in the anterior, septal and inferior walls of the left ventricle in their middle and apical portions was observed. (B) The myocardial perfusion is normal.

patients visiting an emergency department with the transient apical ballooning syndrome are an elevation of the ST-segment associated with an increase in troponin I, as was observed in our patient.

Recently, some cases of reversible left ventricular outflow tract obstruction after Tako-Tsubo syndrome have been reported [7-9], and they hypothesized that an acute ischemic event could produce transient contractile dysfunction and geometric remodeling resulting in systolic anterior motion of the mitral subvalvular apparatus with the occurrence of an end-systolic obstruction [10]. In our patient, echocardiography was performed at admission and detected a severe LVOT obstruction, associated with septal bulge and systolic anterior motion of the mitral valve and mitral regurgitation. This morphological pattern of the interventricular septum is mostly presented in older patients and seems to be an important factor of LVOT obstruction in TakoTsubo syndrome, mimicking a pattern of obstructive hypertrophic cardiomyopathy [11].

\section{Conclusion}

Echocardiography should thus be systematically performed at admission in patients with suspicion of Tako Tsubo syndrome for detection of LVOT obstruction and for guiding treatment. In our patient all clinical and imaging non-invasive studies showed the characteristics of a Tako-Tsubo syndrome with a transient LVOT obstruction.

\section{Limitation}

The limitation of this case report is that coronary angiography or computed tomography had not been performed, because she is in the nine decade of life and her symptoms disappeared with medical treatment and the follow-up left ventricular wall motion and left ventricular function were completely recovered and myocardial perfusion study was normal 3 weeks later. Also the patient has chronic renal insufficiency.

\section{Competing Interest}

The authors declare that they have no competing interests.

\section{Authors' Contributions}

NEZ conceived the case report, performed echocardiographic examinations, reviewed literature and wrote the manuscript. MLJ, VMOA and MLLR has been involved in drafting the manuscript, contributed to the critical revision of the manuscript. NEZ supervised and commented on the manuscript. All authors read and approved the final manuscript.

\section{References}

1. Kurisu S, Sato H, Kawagoe T, Ishihara M, Shimatani Y, et al. (2002) Tako-Tsubo 
Citation: Espinola-Zavaleta N, Levinstein-Jacinto M, Ocana-Arriaga VM, Llata-Romero M (2017) Transient Left Ventricular Outflow Obstruction in Tako Tsubo- Syndrome: A Case Report. J Vasc Med Surg 5: 350. doi: 10.4172/2329-6925.1000350

Page 3 of 3

like left ventricular dysfunction with ST-segment elevation: a novel cardiac syndrome mimicking acute myocardial infarction. Am Heart J 143: 448-455.

2. Sharkey SW, Lesser JR, Zenovich AG, Maron MS, Lindberg J, et al. (2005) Acute and reversible cardiomyopathy provoked by stress in women from the United States. Circulation 111: 472-479.

3. Wittstein IS, Thiemann DR, Lima JA, Baughman KL, Schulman SP, et al. (2005) Neurohumoral features of myocardial stunning due to sudden emotional stress. N Engl J Med 352: 539-548.

4. Caselli S, Passasseo I, Giannantoni P, Santini D, Marcantonio A, et al. (2008) 2-and 3-dimensional echocardiographic analysis of an unusual transient apical ballooning. J Am Soc Echocardiogr 21: 511.e1-511e4

5. El Mhmoud R, Mansencal N, Pilliére R, Leyer F, Abbou N, et al. (2008) Prevalence and characteristics of left ventricular outflow tract obstruction in Tako-Tsubo syndrome. Am Heart J 156: 543-548.

6. Elliot P, Anderson B, Arbustini E, Bilinska Z, Cecchi F, et al. (2008) Classification of the cardiomyopathies: a position statement from the European Society of
Cardiology working group on myocardial and pericardial diseases. Eur Heart J 29: 270-276.

7. Penas-Lado M, Barriales-Villa R, Goicolea J (2003) Transient left ventricular apical ballooning and outflow tract obstruction. J Am Coll Cardiol 42: 11431144.

8. Chockalingam A, Tejwani L, Aggarwal K, Dellsperger KC (2007) Dynamic left ventricular outflow obstruction in acute myocardial infarction with shock: cause, effect, and coincidence. Circulation 116: e110-e113.

9. Bybee KA, Prasad A (2008) Stress-related cardiomyopathy syndromes Circulation 118: 397-409.

10. Villareal PR, Achari A, Wilansky S, Wilson JM (2001) Anteroapical stunning and left ventricular outflow tract obstruction. Mayo Clin Proc 76: 79-83.

11. Forissier JF, Charron P, Tezenas du Montcel S, Hagege A, Isnard R, et al (2005) Diagnostic accuracy of 2D Left ventricle hypertrophy score for familia hypertrophic cardiomyopathy. Eur Heart J 26: 1882-1886. 